\title{
$B$ cell regulation of the anti-tumor response and role in carcinogenesis
}

\author{
Marc Schwartz ${ }^{2}$ Y Y Zhang ${ }^{1,2,3}$ and Joseph D. Rosenblatt ${ }^{1,2,3^{*}}$
}

\begin{abstract}
The balance between immune effector cells such as T cells and natural killer cells, and immunosuppressive Treg cells, dendritic, myeloid and monocytic sub-populations in the tumor microenvironment acts to calibrate the immune response to malignant cells. Accumulating evidence is pointing to a role for B cells in modulating the immune response to both solid tumors and hematologic cancer. Evidence from murine autoimmune models has defined B regulatory cell (Breg) subsets that express cytokines such as IL-10, TGF- $\beta$, and/or express immune regulatory ligands such as PD-L1, which can suppress T cell and/or natural killer cell responses. Multiple murine tumor models exhibit decreased tumor growth in B cell deficient or B cell depleted mice. In several of these models, B cells inhibit $\mathrm{T}$ cell mediated tumor immunity and/or facilitate conversion of T cells to $\mathrm{CD} 4^{+} \mathrm{CD} 25^{+} \mathrm{FoxP} 3^{+} \mathrm{T}$ regs, which act to attenuate the innate and/or adaptive antitumor immune response.

Mechanisms of suppression include the acquisition of inhibitory ligand expression, and phosphorylation of Stat3, and induction of IL-10 and TGF- $\beta$, resulting in a Breg phenotype. Breg suppressive activity may affect diverse cell subtypes, including T effector cells, NK cells, myeloid derived suppressor cells (MDSC) and/or tumor associated macrophages. B cells may also directly promote tumorigenesis through recruitment of inflammatory cells, and upregulation of pro-angiogenic genes and pro-metastatic collagenases.

Breg infiltration has now been identified in a variety of solid tumor malignancies including but not limited to ovarian, gastric, non-small cell lung cancer, pancreatic, esophageal, head and neck, and hepatocellular carcinomas. Increasing evidence suggests that recruitment of B cells and acquisition of suppressive activity within the tumor bed may be an important mechanism through which B cells may modulate innate and/or adaptive anti-tumor immunity. B cell depletion in the clinic using anti-CD20 antibodies and/or inhibitors of BTK and/or other signaling pathways, may be a useful strategy for augmenting the anti-tumor immune response.
\end{abstract}

Keywords: B regulatory cells, Anti-tumor immunity, Carcinogenesis

\section{Background}

A subset of B cells identified as B-regulatory cells (Bregs) have recently emerged as major contributors to the pathogenesis of autoimmune and neoplastic disorders. In neoplastic disorders, Bregs are generated in response to signals from the tumor microenvironment and in turn promote tumor growth through interactions with $\mathrm{T}$ regulatory cells (Tregs), myeloid-derived suppressor cells (MDSC), tumor-associated macrophages, $\mathrm{CD}^{+}$and

\footnotetext{
* Correspondence: jrosenblatt@med.miami.edu

'Division of Hematology/Oncology, Department of Medicine, University of Miami Miller School of Medicine and Sylvester Comprehensive Cancer Center, 1120 NW 14th St., CRB 610, Miami, FL 33136, USA

${ }^{2}$ Department of Medicine, University of Miami Miller School of Medicine, 1120 NW 14th St., CRB 610, Miami, FL 33136, USA

Full list of author information is available at the end of the article
}

$\mathrm{CD}^{+} \mathrm{T}$ lymphocytes, natural killer (NK) cells, and direct interactions with tumor cells. A role for B cells in anti-tumor immunity was first established by Brodt and Gordon [1] and Monach et al. [2], who demonstrated that tumor growth was diminished in B-cell depleted mice. Qin et al. [3] and Shah et al. [4] later demonstrated that B cells inhibit CTL-mediated tumor immunity. More recently Olkhanud et al. [5] and Tadmor et al. [6] showed that Bregs may facilitate the conversion of CD4 ${ }^{+} \mathrm{CD} 25^{-} \mathrm{T}$ cells to $\mathrm{CD} 4^{+} \mathrm{CD} 25^{+} \mathrm{FoxP}^{+}$Tregs, which in turn attenuate the innate anti-tumor cellular immune response.

Effects of Breg cells in murine tumor models suggested that similar B regulatory activity would also be identified in human tumors. While some studies suggest 
that tumor-infiltrating $\mathrm{B}$ cells have a protective role against disease progression [7-12], other studies suggest that Bregs are upregulated in patients with solid tumor malignancies and are associated with enhanced tumoraggressiveness and poorer prognosis [13-25]. In human lymphoid malignancies, malignant $\mathrm{B}$ cells appear to act as Bregs by suppressing the anti-tumor cellular immune response through expression of suppressive ligands [2629]. This has led to successful targeting of B-regulatory functions of malignant B cells in lymphomas, which have thus far shown remarkably favorable outcomes in several clinical trials [26-28]. These results have lent credence to the notion that Breg activity may be modulating immune responses against non-lymphoid solid tumors. Bregs have now been identified in humans with a variety of solid tumor malignancies including ovarian, gastric, lung, colorectal, pancreatic, breast, esophageal, bladder, squamous cell, and hepatocellular carcinomas [13-22, 24, 25]. These observations suggest that targeting of Breg activity may be used to enhance immunotherapeutic outcomes.

\section{Breg subtypes in autoimmune disease and cancer}

\section{I.) Role of IL-10 in B cell regulatory function}

IL-10 exerts anti-inflammatory effects in mouse and human cells via suppression of $\mathrm{Th}_{1}$ and $\mathrm{Th}_{17}$ responses, promotion of $\mathrm{CD}^{+} \mathrm{CD} 25^{+} \mathrm{FoxP}^{+}$Treg generation, and suppression of the release of macrophage- and monocyteproduced inflammatory cytokines [30-33]. B cells with regulatory function were initially described in murine models of autoimmune diseases such as experimental autoimmune encephalitis (EAE), collagen-induced arthritis (CIA), and inflammatory bowel disease (IBD), in which B cell deficient mice developed severe nonremitting disease that was ameliorated with $\mathrm{B}$ cell adoptive transfer [15-20, 34-39]. Fillatreau et al. [36] showed that mice which had recovered from EAE produced IL-10 in response to autoantigen, while mice incapable of producing IL-10 developed severe non-remitting EAE. Mice with IL-10 deficiency restricted to B cells also developed severe non-remitting EAE, which could be ameliorated through the adoptive transfer of IL-10-producing B cells from wild type (WT) mice that had recovered from EAE. CD40-CD40L interaction was recognized as an essential step in the generation of IL-10-producing B cells in response to autoantigen [36]. This and similar results in other mouse autoimmune models [32-34, 38-42] implicated IL-10 as a principal effector of B cell immuneregulatory activity. Decreased frequency and dysfunction of IL- $10^{+}$Bregs have been described in humans with various autoimmune disorders such as rheumatoid arthritis, systemic lupus erythematosus (SLE), inflammatory bowel disease, graft-versus-host disease, and vasculitides [4352]. Enhancement of peripheral and organ-specific Bregs has been shown to be protective in patients with severe acute pancreatitis [53] but also has been associated with advanced histological fibrosis stages in patients with chronic hepatitis B virus infection [54], suggesting that Breg-mediated immune suppression may be beneficial in acute inflammatory states but harmful in chronic infectionmediated inflammatory states.

\section{II.) Phenotypic markers of Bregs}

In early mouse studies, IL-10 production was shown to be restricted mainly to a CD1d ${ }^{\text {hi }} \mathrm{CD} 5^{+}$("B10") subset that comprised roughly $1-3 \%$ of splenic B cells $[37,38]$. Other phenotypically distinct B cell subsets identified in humans exhibit immune regulatory properties through both IL-10 dependent and independent mechanisms. Iwata et al. [25] showed that IL-10-producing B cells in humans were predominantly found within a CD24 ${ }^{\text {hi }} \mathrm{CD} 27^{+}$ subset that was capable of suppressing monocyte cytokine production in vitro. Blair et al. [44] demonstrated that human $\mathrm{CD} 19^{+} \mathrm{CD} 24^{\text {hi }} \mathrm{CD} 38^{\text {hi }}$ peripheral blood B cells suppressed $\mathrm{CD}^{+}{ }^{+} \mathrm{T}$ cell IFN- $\gamma$ and TNF- $\alpha$ production in vitro, with suppressive activity that was dependent on IL-10, CD80, and CD86. The latter two membrane proteins are key ligands for CTLA-4, a co-inhibitory immune checkpoint receptor expressed on activated effector $\mathrm{T}$ cells and Tregs $[53,55]$. CD $19^{+} \mathrm{CD} 25^{\text {hi }} \mathrm{B}$ cells have also been suggested to represent a Breg population in humans with the capability of suppressing $\mathrm{CD}^{+}{ }^{+} \mathrm{T}$ cell proliferation and enhancing CTLA-4 and FoxP3 expression on Treg cells in vitro, in a manner dependent on TGF- $\beta$ but not IL-10 [56]. $\mathrm{CD}^{+} \mathrm{B}$ cells have also been implicated in the suppression of anti-tumor immunity in humans through activation of Stat3 [57], a transcription factor that may be involved in production of IL-10 [58].

Additional B cell expressed surface antigens have been shown to confer regulatory properties. Programmed Death 1 Ligand (PD-L1) interacts with PD-1 on T cells to induce tolerance and limit effector $\mathrm{T}$ cell responses [59], and has recently shown to be expressed on human malignant B cells in several types of lymphoma including diffuse large B cell lymphoma (DLBCL), Hodgkin's lymphoma, and follicular lymphoma [26-28]. Fas-Ligand (FasL), a member of the tumor necrosis factor pathway, interacts with its receptor FasR (CD95) to initiate a signaling cascade leading to apoptosis. B cell expressed Fas- $\mathrm{L}$ has been implicated in the induction of $\mathrm{T}_{\mathrm{H}}$ cell apoptosis in HIV and EBV infections [60], and Fas-L expression on malignant B cells in lymphoid cancers such as chronic lymphocytic leukemia (CLL) may play a role in inhibiting anti-tumor responses by inducing $\mathrm{T}_{\mathrm{H}}$ cell apoptosis [61]. Lindner et al. demonstrated that human 
Granzyme B-producing $\left(\mathrm{GrB}^{+}\right)$B cells are induced by IL-21-secreting $T$ cells, which in turn function to suppress $\mathrm{T}$ cell proliferation via $\mathrm{GrB}$-dependent degradation of the $\mathrm{T}$ cell receptor (TCR)- $\zeta$-chain in vitro. $\mathrm{GrB}^{+}$Bregs and adjacent IL-21-producing $\mathrm{T}$ cells were found in the microenvironment of several human tumors including breast, ovarian, cervical, colorectal, and prostate tumors [62]. These findings suggest that IL-21-dependent $\mathrm{GrB}^{+}$ Bregs may attenuate local anti-tumor immune responses in a manner similar to Tregs, by directly inhibiting the proliferation of $\mathrm{CD}_{4}^{+}$and $\mathrm{CD} 8^{+}$effector T cells.

\section{B regulatory cells suppress cellular immune responses and promote tumor growth in vivo through diverse mechanisms}

I) Bregs promote tumor growth and metastasis through generation of Treg cells and suppression of effector $\mathrm{T}$ cell and NK cell responses

Several murine tumors including the MC38 colorectal cancer, EL4 thymoma, and EMT-6 mammary carcinoma models demonstrate reduced or absent growth in B-cell deficient mice (BCDM) compared to WT mice $[4,6,63]$. The anti-tumor effect conferred by B cell deficiency in all three models was associated with increased $\mathrm{T}$ cell and NK cell infiltration and more vigorous Th1 cytokine and cytolytic T cell responses, and in EMT-6 was also associated with decreased proliferation of $\mathrm{CD}^{+} \mathrm{FoxP}^{+}$Tregs. Adoptive transfer of B cells from WT mice into tumorbearing BCDM restored tumor growth and Treg proliferation and diminished $\mathrm{CD}^{+} \mathrm{IFN}-\gamma^{+}$and $\mathrm{NK}$ cell infiltration into the tumor bed. Interestingly, in contrast to several autoimmune models the adoptive transfer of either WT or IL-10 ${ }^{-1-}$ B cells was capable of rescuing tumor growth in the EMT-6 model [63]. In the MC38 model, adoptive transfer of $\mathrm{OX}_{40 \mathrm{~L}^{-/-}} \mathrm{B}$ cells was less efficient in rescuing tumor growth than WT B cell transfer, demonstrating a role for cognate interactions between OX40L and OX40 on B cells and T cells respectively in modulating the anti-tumor response [64].

Pulmonary metastasis of murine 4 T1 breast cancer requires inactivation of antitumor NK cells and expansion of Treg cells [5, 65]. Olkhanud et al. [5] identified a $\mathrm{CD} 25^{+} \mathrm{CD} 19^{+} \mathrm{B} 220^{+} \mathrm{B}$ cell subset designated as tumorevoked Bregs (tBregs), that constitutively expressed Stat3 and was expanded in $4 \mathrm{~T} 1$ tumor-bearing mice. In vitro, mouse B cells treated with cancer cell-derived cultured media (CM) but not control CM was able to suppress $\mathrm{T}$ cell proliferation. Furthermore, $\mathrm{T}$ cell inhibitory activity was restricted to $\mathrm{CD} 25^{+}$, but not $\mathrm{CD} 25^{-}$cancer-CM treated B cells. Interestingly, peripheral blood CD19 ${ }^{+} \mathrm{B}$ cells from healthy human donors treated with ovarianand colon-cancer cell-derived CM upregulated CD25 and suppressed $\mathrm{T}$ cell proliferation in vitro as well, suggesting that human tumors may also induce a suppressive $\mathrm{CD} 25^{+}$Breg population.

Non-regulatory mouse $\mathrm{CD} 4^{+} \mathrm{CD} 25^{-} \mathrm{FoxP} 3^{-} \mathrm{T}$ cells developed increased expression of FoxP3 (thus demonstrating conversion to Tregs) when co-cultured with tBregs, but not control B cells, in a process that was dependent on TGF- $\beta$. WT mice also developed expansion of FoxP3+ Tregs in peripheral blood in vivo when injected with tBregs, but not control B cells. In T- and B-cell deficient NOD/SCID mice in which 4 T1 tumors grow at the primary site but do not metastasize, lung metastasis was restored with adoptive transfer of ex vivo converted Tregs (but not non-Tregs) or with the transfer of tBregs together with non-Tregs (but not tBregs alone), thereby demonstrating that lung metastasis of $4 \mathrm{~T} 1 \mathrm{tu}-$ mors was dependent on tBreg-mediated conversion of non-Tregs to Tregs in vivo. These results indicate that a unique $\mathrm{CD} 25^{+} \mathrm{CD} 19^{+} \mathrm{B} 220^{+} \mathrm{B}$ cell subset that constitutively expresses Stat 3 may be expanded by tumors, and may in turn promote tumor metastasis through TGF $\beta$ dependent conversion of non-Tregs to Tregs $[5,66]$.

\section{II) Bregs impair antigen-specific anti-tumor vaccines} through suppression of $\mathrm{T}$ and NK cell responses

Consistent with B regulatory cells having an immunesuppressive function, antigen-specific anti-tumor vaccines have been demonstrated to be more effective in the absence of B cells in several mouse tumor models. In the B16 melanoma mouse model, vaccination against either of the tumor-associated antigens (TAA) gp100 or TRP-2 using adenovirus-based vectors suppressed tumor growth in B-cell deficient, but not WT mice. The enhanced antitumor response against B16-associated tumor antigens in BCDM was dependent on the presence of NK cells [67]. In EL-4 thymoma implanted mice, Oizumi et al. [68] demonstrated using a highly immunogenic secreted form of gp96 heat shock protein as a vaccine, that effective tumor antigen-specific gp96-chaperone vaccination was achieved with a single vaccination in $\mathrm{BCDM}$, while repeated vaccinations were required to achieve a similar level of immunity in WT mice. Increased $\mathrm{CD}^{+}$cytotoxic responses directed against EL-4-associated tumor antigens were observed in vaccinated BCDM compared to vaccinated WT mice. These results indicated that inhibition of effects mediated by immune-suppressive Breg cells may help maximize anti-tumor responses induced by vaccination.

III) Tumor-infiltrating B cells acquire LAP/TGF $\beta$ and PD-L1 expression and suppress T and NK cell responses

EMT-6 mammary tumors are rejected or show markedly diminished growth in BCDM but growth is restored 
in BCDM reconstituted with B cells [63]. Using the EMT-6 model Zhang et al. [69] demonstrated that tumor-infiltrating B cells (TIL-B) develop increased expression of LAP/TGF- $\beta$, CD80, CD86, and PD-L1 in vivo compared to splenic $B$ cells. Development of a similar B cell immunosuppressive phenotype also occurred when B cells were co-cultured in vitro with EMT-6 cells, and was dependent on direct physical B cell: tumor cell contact. Functionally, these TIL-B cells demonstrated greater ability to suppress $\mathrm{CD} 4^{+}$and $\mathrm{CD} 8^{+} \mathrm{T}$ cell proliferation in response to anti-CD3/anti-CD28 costimulation, and also markedly suppressed NK cell proliferation in response to IL-15 compared to splenic B cells. Monoclonal antibodies directed against TGF- $\beta$ or PD-L1 dramatically suppressed EMT-6 tumor growth in WT mice, suggesting a potential therapeutic strategy for targeting this specific B cell subpopulation. In addition, TIL-B but not splenic B cells were capable of secreting IL-10 following stimulation, suggesting that an IL-10 secreting subpopulation was predominantly contained within the TIL-B population. These results point to the local acquisition of immunosuppressive properties by $\mathrm{B}$ cells migrating into the tumor bed through intimate contact with the tumor cells. Mechanism(s) underlying this functional transition and migration, as well as evidence for similar activity in human tumors are being actively investigated.

IV) T2-MZP B cells accumulate in tumor-draining lymph nodes and promote metastasis independently of IL-10

B16-F10 melanoma grows significantly more slowly, but is not completely rejected in BCDM relative to WT mice [4]. Marked B cell accumulation in tumor-draining lymph nodes (TDLN) of mice implanted with B16-F10 melanoma tumors precedes the development of metastases. Ganti et al. [70] showed that T2-MZP $\left(B 220^{+} \mathrm{CD} 23\right.$ $\left.{ }^{+} \operatorname{IgM}{ }^{\text {hi }} \mathrm{CD} 21^{\text {hi }}\right)$ B cells preferentially accumulated in the TDLN of tumor-bearing mice. Both tumor-implanted BCDM and WT mice demonstrated accelerated tumor growth when reconstituted with T2-MZP B cells, but not other B cell subtypes. Frequencies of IL-10-secreting $\mathrm{B}$ cells and FoxP3 ${ }^{+}$Tregs were not affected by T2-MZP $B$ cell transfer. In this model, B16-F10 melanoma induces accumulation of T2-MZP Bregs in TDLN, which in turn promote tumor growth and metastasis, and appear to do so independently of IL-10 and/or Tregs. Further investigations are warranted to determine the mechanism of Breg activity in this unique B cell subset.

V) Bregs promote tumor growth and metastasis through "education" of myeloid-derived suppressor cells
MDSCs are key regulators of tumor growth and metastasis in the tumor microenvironment [71]. Using the B16 melanoma model in which tumor growth is inhibited in BCDM but restored with adoptive B cell transfer, Bodogai et al. [72] showed that adoptive transfer of MDSCs from B16-implanted WT mice into tumorbearing $\mathrm{BCDM}$ restored tumor growth to the same degree as did adoptive transfer of B cells from B16implanted WT mice. Conversely, adoptive transfer of MDSCs from B16-implanted $B C D M$ into tumor-bearing $\mathrm{BCDM}$ did not restore metastasis.

In human cell lines, myeloid cells sort-purified from healthy donor PBMCs depleted of T and NK cells and treated with CM from MDA-MB-231 breast cancer cells were able to suppress $\mathrm{T}$-cell proliferation in vitro. However, myeloid cells from donor PBMCs depleted of $\mathrm{T}$, $\mathrm{NK}$, and $B$ cells and treated with cancer-derived CM failed to suppress $\mathrm{T}$ cell proliferation.

These results indicate that the immune-suppressive and tumor-promoting functions of MDSCs may be acquired through "education" by Bregs. The nature of $\mathrm{B}$ cell mediated education of MDSC is unclear, but clearly indicates a role for Breg in modulating myeloid suppressor cell activity, in addition to aforementioned effects on $\mathrm{T}$ and NK cells, thereby shaping the overall immune microenvironment.

VI) The role of Stat3 activated Bregs in promoting tumor growth and metastasis via generation of Treg cells and promotion of angiogenesis

Consistent with the finding that $\mathrm{CD} 19^{+} \mathrm{CD} 25^{+}$tumorevoked Bregs (tBregs) constitutively express Stat 3 and promote tumor growth and metastasis by TGF $\beta$-dependent conversion of non-Tregs to Tregs [5], Lee-Chang et al. [73] demonstrated that treatment with non-cytotoxic doses of resveratrol (RSV), a potent inhibitor of Stat3 phosphorylation, suppressed proliferation of tBregs and FoxP3 $^{+}$Tregs in vitro, and inhibited growth of B16 and $4 \mathrm{~T} 1$ murine tumors in vivo. In in vitro experiments using naïve B cells treated with $4 \mathrm{~T} 1$ cell-derived CM, low-dose RSV blocked tBreg generation, Treg generation, and reversed tBreg/Treg-mediated suppression of $\mathrm{T}$ cell proliferation. tBregs treated with RSV also had decreased expression of phosphorylated Stat3 (pStat3) and TGF $\beta$ compared to mock-treated tBregs. Furthermore, RSVtreated tBregs adoptively transferred into $4 \mathrm{~T} 1$ tumorbearing mice lacked the ability to expand FoxP3 ${ }^{+}$Tregs in vivo and promote lung metastasis as compared to mocktreated tBregs. These findings suggest that inhibition of Stat3 phosphorylation in Bregs, by RSV or other methods, may inhibit tumor growth by preventing the downstream local elaboration of TGF- $\beta$ and subsequent promotion of FoxP3 ${ }^{+}$Tregs. 
JSI-124 (cucurbitacin I), a potent Stat3 inhibitor, also inhibited growth of 4 T1 murine tumors. 4 T1-implanted mice treated with JSI-124 suppressed tumor growth compared to non-treated mice, and B cells isolated from treated mice had decreased expression of Stat3. Consistent with the hypothesis that inhibition of B cell-expressed Stat3 was responsible for the anti-tumor effect of JSI-124, Stat $3{ }^{\text {low }}$ B cells from treated mice exhibited a tumor-suppressive effect when injected into 4. T1-bearing mice, while injection of Stat $3^{\text {high }} \mathrm{B}$ cells from non-treated mice promoted tumor growth [74].

Yang et al. [75] showed that increased tumor growth mediated by Stat3 expression in B cells was associated with increased tumor angiogenesis. In T- and B-cell deficient $\operatorname{Rag} 1^{-1-}$ mice, growth of B16 and Lewis Lung cancer (LLC) tumors was augmented following the adoptive transfer of Stat $3^{+/+}$B cells, while growth was diminished with adoptive transfer of Stat $3^{-/-}$B cells. Augmented tumor growth with $\mathrm{Stat}^{+/+} \mathrm{B}$ cell adoptive transfer was associated with increased tumor angiogenesis in vivo by Matrigel assay and in vitro in B cell: endothelial cell co-culture assays, and increased expression of pro-angiogenic genes by RNA in vivo. TIL-B cells with persistently-activated Stat3 has also been identified in several human tumors including melanoma, gastric, lung, liver, and prostate cancers [75]. Furthermore, Stat3 activity in human tumor tissues was associated with increased density of TIL-B cells and significantly increased intratumoral angiogenesis.

Zhang et al. [57] recently showed that CD5 positivity among CD19 cells strongly correlated with levels of Stat3 expression in human lung and prostate tumor tissues and in corresponding TDLN, indicating that Stat3expressing Bregs may be contained within a $\mathrm{CD} 5^{+} \mathrm{B}$ cell population in human tumors.

Collectively these studies indicate an important role for Stat3 in conferring an immunosuppressive phenotype to Breg cells, mediated in part through local elaboration of TGF- $\beta$ and through the induction of pro-angiogenic gene expression. Inhibition of Stat 3 signaling may therefore be a useful means of reducing or reversing Breg promotion of tumor growth.

VII) CD $19^{ \pm} \mathrm{CD} 1 \mathrm{~d}^{\text {high }} \mathrm{CD} 5^{ \pm}$Bregs infiltrate pancreatic neoplasms and mediate tumor growth via IL-35 signaling

Pylayeva-Gupta et al. [76] recently showed that prominent $B$ cell infiltrates are frequently present in human pancreatic intraepithelial neoplasia (PanIN) and in pancreata of mice harboring Kras-driven pancreatic neoplasms. In addition, implantation of pancreatic ductal epithelial cells expressing oncogenic $\mathrm{Kras}$ ( $\mathrm{Kras}^{\mathrm{G} 12 \mathrm{D}}$ ) into WT mice pancreata leads to infiltration of B cells adjacent to the newly developing tumor. Kras ${ }^{\mathrm{G} 2 \mathrm{D}}$ pancreatic tumor growth is diminished in BCDM but tumor growth is restored following B cell adoptive transfer, which is accompanied by de novo tumor infiltration with the adoptively transferred $\mathrm{B}$ cells.

Since the $\mathrm{CD} 1 \mathrm{~d}^{\mathrm{hi}} \mathrm{CD}^{+}$B cell population has been shown to mediate immune-suppression via IL-10 secretion [37, 38] and IL-35 [77] in mouse autoimmune and tumor models, Pylayeva-Gupta et al. investigators hypothesized that $\mathrm{CD} 1 \mathrm{~d}^{\mathrm{hi}} \mathrm{CD}^{+} \mathrm{B}$ cells would also regulate immune-suppression and promote tumor growth in the mouse pancreatic ductal adenocarcinoma (PDAC) model. Adoptive transfer of $\mathrm{CD} 19^{+} \mathrm{CD} 1 \mathrm{~d}^{\text {hi }} \mathrm{CD}^{+} \mathrm{B}$ cells but not $\mathrm{CD} 19^{+} \mathrm{CD} 1 \mathrm{~d}^{\mathrm{lo}} \mathrm{CD} 5^{-} \mathrm{B}$ cells rescued tumor growth in BCDM inoculated with Kras ${ }^{\mathrm{G} 12 \mathrm{D}}$. Adoptive transfer of IL$10^{-/-} \mathrm{B}$ cells was capable of rescuing tumor growth in $\mathrm{BCDM}$ inoculated with $\mathrm{Kras}^{\mathrm{G}}{ }^{2 \mathrm{D}}$ to the same extent as WT B cells, however tumor growth remained suppressed with adoptive transfer of IL-12 $\alpha^{-/-}$B cells, indicating that promotion of tumor growth by infiltrating $\mathrm{CD} 1 \mathrm{~d}^{\text {hi }} \mathrm{CD}^{+} \mathrm{B}$ cells in this PDAC model is mediated by IL-35, a heterodimer comprised of p35 and EBI3 subunits encoded by the genes IL12 $\alpha$ and EBI3, respectively.

IL- $35^{+}$Bregs have been shown to inhibit $\mathrm{Th}_{1}$ and $\mathrm{Th}_{17}$ cells and promote Treg expansion in a mouse model of autoimmune uveitis [77]. IL-35 has also been shown to promote growth of human pancreatic cancer cells in vitro [78], and has been shown to be upregulated in the sera of patients with pancreatic cancer [79]. Together, these results suggest that B cells may infiltrate pancreatic neoplasms and promote tumor growth via suppression of antitumor immunity through IL-35 secretion. IL35 mediated Breg suppression of tumor immunity may also be a suitable target for therapeutic intervention in select human tumors.

VIII) Bruton's tyrosine kinase (BTK) expression in B cells and macrophages, as a target for regulation of immune-suppressive phenotypes

Previous findings by Affara et al. [80] and Andreu et al. [81] suggested that TIL-B cells promote tumor growth in squamous cell carcinoma (SCC) models through interactions with Ig receptor $\mathrm{FcR} \gamma+$ myeloid cells and subsequent repolarization of TAM towards an immunesuppressive type ("M2"-type). Gunderson et al. [82] showed that mouse PDAC tumors were heavily infiltrated with $\mathrm{B}$ cells and FcRy + myeloid cells, and furthermore that tumor growth was diminished in BCDM and Ig-receptor null $\mathrm{FcR}^{-1-}$ mice. Based on these observations, investigators hypothesized that signaling pathways common to both B cells and macrophages, such as BTK signaling, may be involved in the suppression of antitumor immunity by infiltrating lymphocytes in PDAC tumors. In accordance with this hypothesis, 
activated BTK (pBTK) was identified in murine PDAC tumors in single-cell suspensions and was most prominent in $\mathrm{CD} 19^{+} \mathrm{B}$ cells and $\mathrm{CD} 11 \mathrm{~b}^{+}$myeloid cells.

In in vitro assays using PDAC-derived $\mathrm{B}$ cells cocultured with macrophages, PDAC-derived B cells enhanced macrophage expression of Th2 cytokines. In contrast, the pre-treatment of PDAC-derived B cells with the BTK inhibitor ibrutinib instead enhanced macrophage expression of Th1 cytokines. These results indicate that inhibition of BTK in tumor-infiltrating B cells may promote macrophage repolarization from an immune-suppressive, tumorigenic M2-type toward a pro-inflammatory, anti-tumor M1-type.

In vivo, early stage PDAC tumor-bearing mice treated with ibrutinib exhibited significantly diminished tumor growth. Treatment of late-stage tumor-bearing mice treated with ibrutinib plus gemcitabine resulted in significantly diminished tumor growth compared to gemcitabine alone. BTK may therefore represent a novel potential target for reduction of Breg cell activity in cancer, and furthermore BTK inhibition may augment the efficacy of chemotherapy.

Ibrutinib has recently been approved by the FDA for treatment of patients with refractory or p53-mutated CLL [83], as well as patients with relapsed mantle cell lymphoma [84]. These findings have provided a rationale for clinical trials examining the use of ibrutinib as adjunctive therapy to gemcitabine and nab-paclitaxel in metastatic pancreatic carcinoma (NCT02562898, NCT02436668).

IX) A link between 4-1BBL expression on B cells and the generation of cytotoxic Granzyme- $\mathrm{B}^{+} \mathrm{T}$ cells

Interestingly, depletion of B cells with an anti-CD20 antibody $(\alpha-C D 20 \mathrm{mAb})$ in WT mice prior to inoculation with $4 \mathrm{~T} 1$ cells blocked metastasis of $4 \mathrm{~T} 1$ tumor, consistent with findings observed in genetically B-cell deficient mice [85]. However, administration of $\alpha$-CD20 $\mathrm{mAb}$ to WT mice with established $4 \mathrm{~T} 1$ tumors unexpectedly resulted in significantly enhanced tumor growth and metastasis.

Bodogai et al. [85] reconciled this paradoxical result by demonstrating that $\alpha-\mathrm{CD} 20 \mathrm{mAb}$ treatment of $4 \mathrm{~T} 1$ tumor-bearing mice enriches for $\mathrm{B}$ cells that are phenotypically $\mathrm{CD} 20^{\text {low }}$ and have enhanced $\mathrm{T}$ cell-suppressive effects ex vivo compared to B cells from control IgG2atreated tumor-bearing mice. Consistent with these findings in mice, co-culture of human peripheral blood B cells with human breast cancer or colon cancer cells resulted in emergence of a CD20 ${ }^{\text {low }}$ Breg population that suppressed T-cell activity and was sustained after treatment with $\alpha-\mathrm{CD} 20 \mathrm{mAb}$ in vitro.

Screening for TLR ligands capable of inactivating Bregs revealed that the TLR9 ligand CpG-ODN was able to upregulate CD20 and block the T cell-suppressive effects of human and murine tBregs in vitro. Treatment of 4 T1 tumor-bearing mice with CpG-ODN abrogated lung metastasis, and ex vivo B cells derived from CpGODN treated tumor-bearing mice induced $\mathrm{T}$ cell proliferation and expansion of $\mathrm{GrB}^{+} \mathrm{CD}^{+}$cytolytic $\mathrm{T}$ cells. Enhancement of metastasis by $\alpha-C D 20 \mathrm{mAb}$ treatment was completely reversed in vivo when $\alpha-C D 20 \mathrm{mAb}$ treated tumor-bearing mice were adoptively transferred with CpG-ODN-pretreated B cells from syngeneic naïve mice. In contrast, adoptive transfer of mock-treated $B$ cells minimally reduced the enhanced lung metastasis following $\alpha$-CD20 mAb treatment.

4-1BBL (CD137L) is an immune co-stimulatory receptor and a member of the TNF receptor family, which activates $\mathrm{CD} 8^{+} \mathrm{T}$ cells and NK cells via cross-linking of 4-1BB (CD137) expressed primarily on T cells [86]. Bodogai et al. [85] investigators observed that human and murine $\mathrm{CD} 20^{\text {low }}$ Bregs also had reduced 4-1BBL expression compared to normal B cells. Treatment with CpGODN reversed the reduced expression of $4-1 \mathrm{BBL}$ on murine and human Bregs in vitro as well as in vivo in tumor-bearing mice, resulting in emergence of a CD20 $0^{\text {high }} 4$ $1 B B L^{\text {high }} B$ cell subset.

Consistent with the results seen in the $4 \mathrm{~T} 1$ murine model, the depletion of B cells using $\alpha$-CD20 mAb in mice inoculated with EMT-6 did not result in tumor rejection as expected, and was associated with a paradoxical increase of $\mathrm{CD}^{+} \mathrm{FoxP}^{+}$Tregs in the spleens of treated mice, although a role for 4-1BBL was not investigated in the EMT-6 model [63].

These results suggest that tumors can induce a population of $\mathrm{CD} 20^{\text {low }} 4-1 \mathrm{BBL}^{\text {low }}$ immune-suppressive Bregs that are relatively enriched following $\alpha-\mathrm{CD} 20 \mathrm{mAb}$ treatment. Relative enrichment of CD20 ${ }^{\text {low }} 4-1 \mathrm{BBL}^{\text {low }}$ Bregs therefore is a plausible explanation for the failure of rituximab to provide a clinical benefit when combined with IL-2 immunotherapy for patients with renal cell carcinoma and melanoma [87]. Treatment strategies directed toward facilitating the conversion of $4-1 \mathrm{BBL}^{\text {low }}$ Bregs to immune-stimulatory $4-1 \mathrm{BBL}^{\text {high }} \mathrm{B}$ cells, as demonstrated using CpG-ODN in the 4 T1 model [85], may therefore be a useful strategy to reverse tumormediated induction of suppressive Bregs.

X) $\operatorname{IgA}{ }^{+} \mathrm{CD} 138^{+} \mathrm{PD}-\mathrm{L}^{+} \mathrm{IL}^{-10^{+}}$Bregs impede expansion of anti-tumor cytotoxic T-lymphocytes (CTL) induced by oxaliplatin chemotherapy

In both the TRAMP and Myc-Cap (MC) mouse models of metastatic prostate carcinoma (PC), large tumors ( $>0.7 \mathrm{~g},>350-400 \mathrm{~mm}^{3}$ respectively) were resistant to treatment with low-dose oxaliplatin in WT mice but were sensitive to treatment in BCDM [88]. The anti- 
tumor effect conferred by B cell deficiency was associated with enhanced CD8+ cell infiltration in both tumor types. Treatment of tumor-bearing WT mice with oxaliplatin was associated with emergence of a tumorinfiltrating $\mathrm{CD}_{1} 9^{+} \mathrm{CD} 138^{+} \mathrm{IgA}^{+}$plasma cell population that expressed IL-10, PD-L1, phosphorylated Stat3, and Fas-L. Reconstitution of tumor-bearing BCDM with WT B cells, but not PD-L1 $1^{-/-}$or IL- $10^{-/-} \mathrm{B}$ cells, could restore tumor growth in oxaliplatin-treated mice, implicating both PD-L1 and IL-10 in mediating the Breg suppressive effects. In addition, ablation of B cell TGF $\beta 22$ inhibited oxaliplatin-induced IgA ${ }^{+}$plasma cell generation, blocked induction of tumoral PD-L1 ${ }^{+}$by oxaliplatin and was associated with increased tumoral CTL density and IFN- $\gamma$ production, thus implicating TGF- $\beta$ signaling in the generation of this Breg subpopulation. Large MC tumors resistant to treatment with oxaliplatin monotherapy showed diminished tumor growth when treated with oxaliplatin plus anti-PD-L1, but not with anti-PD-L1 alone.

In human prostatectomy samples, $\mathrm{CD}^{+}$and $\mathrm{CD} 20^{+}$ cell density was higher in patients with PC compared to healthy controls, and correlated significantly with advanced stage and treatment failure [88]. IL-10-producing $\mathrm{IgA}^{+} \mathrm{CD} 138^{+}$plasma cells were also present in human PC samples but were more abundant in metastatic PC and therapy-resistant PC compared to early stage disease.

These results indicate that treatment with an immunogenic chemotherapeutic agent, oxaliplatin, may induce a CD $138^{+} \mathrm{IgA}{ }^{+} \mathrm{PD}-\mathrm{L} 1^{+} \mathrm{IL}^{-10^{+}}$Breg population generated via a TGF $\beta$-dependent pathway that limits the effectiveness of oxaliplatin by inhibiting intratumoral CTL infiltration. This further suggests that the successful treatment of large prostate tumors with oxaliplatin may require the elimination of these immunosuppressive IgA + plasma cells that are present in both mouse and human PC, and suggests a rational approach to augmenting beneficial chemotherapy effects on the anti-tumor immune response. Targeting of the PD-L1/PD-1 axis may be an especially useful strategy in this regard.

A summary of reported B reg phenotypic markers and functional attributes is presented in Table 1, and several of the key reported interactions reviewed above are schematically represented in Fig. 1.

\section{B cell effects on carcinogenesis}

I) B cells are involved in de novo carcinogenesis in murine models of inflammation-associated squamous cell carcinoma

Several landmark studies also point to a role for B cells in facilitating carcinogenesis, mediated through effects on local inflammation $[80,81,89,90]$. In the K14-HPV16 (HPV16) transgenic mouse model of inflammation- associated de novo epithelial carcinogenesis, the absence of T- and B-lymphocytes (generated by intercrossing with Rag $1^{-1-}$ mice) limits immune cell infiltration and attenuates characteristic markers of premalignancy such as VEGF-A activity, matrix metalloproteinase activity, epithelial hyperproliferation, and development of angiogenic vasculature [89]. Subsequently, neoplastic progression is abrograted in HPV16/Rag1 ${ }^{-/-}$mice. Premalignant HPV16 skin was characterized by enhanced immunoglobulin (Ig) deposition, suggesting that B cells initiate Ig deposition into neoplastic tissue, paralleling inflammation and premalignant progression in HPV16 mice. Accordingly, skin from HPV16/Rag1 $1^{-1-}$ mice had diminished Ig deposition and reduced immune cell infiltration. Adoptive transfer of B cells or serum, but not $\mathrm{T}$ cells from HPV16 mice into HPV16/Rag1 $1^{-/}$mice restored Ig deposition, innate immune cell infiltration and premalignant characteristics and facilitated progression to epithelial carcinogenesis.

Based on these findings, Affara et al. [80] showed that $B$ cell depletion with $\alpha$-CD20 mAb restricted premalignant progression in K14-HPV16 transgenic mice. In contrast, $\alpha-\mathrm{CD} 20 \mathrm{mAb}$ treatment did not affect growth of SCC tumors derived from K14-HPV16 mice that were orthotopically implanted into syngeneic WT mice. However, $\alpha-C D 20 \mathrm{mAb}$ treatment in combination with the chemotherapy (CTX) agents cisplatin, carboplatin, or paclitaxel, each ineffective on their own, resulted in tumor regression in mice orthotopically implanted with SCC tumors. Further analysis revealed that combinatorial $\alpha-\mathrm{CD} 20 \mathrm{mAb} / \mathrm{CTX}$ treatment was associated with increased tumor $\mathrm{CD}^{+}$infiltration compared to CTX treatment alone. Similar to aforementioned findings in a mouse model of prostate cancer [88], these results indicate the efficacy of augmenting chemotherapy with Bcell depletion strategies to improve outcomes.

Based on the findings implicating B cells in squamous carcinogenesis in mice [80, 89], and other previous studies showing that TNF- $\alpha$ deficient mice are resistant to chemical carcinogenesis of the skin [91], Schioppa et al. [90] investigators hypothesized that TNF- $\alpha$ might be involved in the tumor-promoting actions of B cells.

In a 7,12-dimethylbenz $[\alpha]$ anthracene/terephthalic acid (DMBA/TPA) mouse model of chemical-induced skin carcinogenesis, DMBA/TPA-induced papilloma development was blocked in B- and T-cell deficient Rag2 $2^{-/}$ mice. Reconstitution of DMBA/TPA-treated Rag2 $2^{-/}$ mice with B cells from DMBA/TPA-treated WT mice restored papilloma growth, whereas reconstitution with $\mathrm{B}$ cells from DMBA/TPA-treated $\mathrm{TNF}^{-1-}$ mice failed to restore papilloma growth, thereby implicating TNF $\alpha$ producing $\mathrm{B}$ cells as key mediators of tumorigenesis in this model. $\mathrm{TNF}^{-1-}$ mice treated with DMBA/TPA also had reduced absolute numbers of splenic $\mathrm{IL}-10^{+} \mathrm{CD} 19^{+}$ cells and increased absolute numbers of $\mathrm{CD}^{+} \mathrm{IFN}-\gamma^{+} \mathrm{T}$ 
Table 1 Breg markers of immune suppression and tumorigenesis

\begin{tabular}{|c|c|c|c|c|}
\hline Breg marker & Mechanisms & Phenotype(s) & Cancer type(s) & References \\
\hline \multirow[t]{8}{*}{ IL-10 } & \multirow[t]{8}{*}{$\downarrow$ Th1/Th17; $\uparrow$ Treg generation } & Human: & \multirow{8}{*}{$\begin{array}{l}\text { HNSCC, lung, esophageal, ovarian, } \\
\text { glioma, gastric }\end{array}$} & \multirow{8}{*}{$\begin{array}{l}{[5,13-22,25,37} \\
38,44,56,65]\end{array}$} \\
\hline & & $\mathrm{CD} 19^{+} \mathrm{CD} 24^{\mathrm{hi}} \mathrm{CD} 38^{\mathrm{hi}}$ & & \\
\hline & & $\mathrm{CD} 19^{+} \mathrm{CD} 1 \mathrm{~d}^{\mathrm{hi}} \mathrm{CD}^{+}$ & & \\
\hline & & $\mathrm{CD} 19^{+} \mathrm{CD} 24^{\mathrm{hi}} \mathrm{CD} 27^{+}$ & & \\
\hline & & $\mathrm{CD} 19^{+} \mathrm{CD} 25^{\mathrm{hi}}$ & & \\
\hline & & Mouse: & & \\
\hline & & $\mathrm{CD} 19^{+} \mathrm{CD} 1 \mathrm{~d}^{\mathrm{hi}} \mathrm{CD} 5^{+}$ & & \\
\hline & & $\mathrm{CD} 19+\mathrm{CD} 25+\mathrm{B} 220+$ & & \\
\hline \multirow[t]{2}{*}{ Granzyme-B } & \multirow{2}{*}{$\begin{array}{l}\downarrow T \text { cell proliferation via degradation of } \\
\text { TCR-zeta chain }\end{array}$} & Human: & \multirow{2}{*}{$\begin{array}{l}\text { Breast, ovarian, cervical, colorectal, } \\
\text { prostate }\end{array}$} & \multirow[t]{2}{*}[62]{} \\
\hline & & $\begin{array}{l}\text { CD19+ CD38+ CD1d + } \\
\lg M+\text { CD147+ }\end{array}$ & & \\
\hline \multirow[t]{4}{*}{ IL-35 } & \multirow[t]{4}{*}{$\downarrow$ Th1/Th17; $\uparrow$ Treg generation } & Human: & \multirow[t]{4}{*}{ Pancreatic } & \multirow[t]{4}{*}[76-79]{} \\
\hline & & CD19+CD35+ & & \\
\hline & & Mouse: & & \\
\hline & & $\mathrm{CD} 19^{+} \mathrm{CD} 1 \mathrm{~d}^{\mathrm{hi}} \mathrm{CD}^{+}$ & & \\
\hline \multirow[t]{4}{*}{ TGF $\beta$} & \multirow[t]{4}{*}{$\uparrow$ Treg generation } & Human: & \multirow[t]{4}{*}{ Multiple tumor types } & \multirow[t]{4}{*}[5,20,44,65]{} \\
\hline & & $\mathrm{CD} 19^{+} \mathrm{CD} 24^{\mathrm{hi}} \mathrm{CD} 38^{\mathrm{hi}}$ & & \\
\hline & & Mouse: & & \\
\hline & & $\mathrm{CD}_{19}{ }^{+} \mathrm{CD} 25^{+} \mathrm{B} 22 \mathrm{O}^{+}$ & & \\
\hline \multirow[t]{4}{*}{ Stat3 } & \multirow[t]{3}{*}{$\uparrow$ Treg generation; $\uparrow$ angiogenesis } & Human: & \multirow{4}{*}{$\begin{array}{l}\text { Melanoma, gastric, lung, liver, } \\
\text { prostate }\end{array}$} & \multirow[t]{4}{*}[57,73-75]{} \\
\hline & & CD5+ & & \\
\hline & & Mouse: & & \\
\hline & $\uparrow I L-10, \uparrow T G F \beta$ & $\mathrm{CD}_{19}{ }^{+} \mathrm{CD} 25^{+} \mathrm{B} 22 \mathrm{O}^{+}$ & & \\
\hline \multirow[t]{2}{*}{ Lymphotoxin- $\alpha / \beta$} & \multirow[t]{2}{*}{ Activation of IKKa and STAT3 } & Mouse: & \multirow[t]{2}{*}{ Castration-resistant prostate (mice) } & \multirow[t]{2}{*}{ [93] } \\
\hline & & $\mathrm{CD} 19+\mathrm{LT}+$ & & \\
\hline \multirow[t]{5}{*}{ PD-L1 } & \multirow{5}{*}{$\begin{array}{l}\text { Promote T cell anergy via interaction } \\
\text { with PD1 }\end{array}$} & Human: & B cell lymphomas, prostate & {$[26-28,69,88]$} \\
\hline & & Malignant B cells & & \\
\hline & & $\lg A+C D 138+$ & & \\
\hline & & Mouse: & & \\
\hline & & $\lg A+C D 138+$ & & \\
\hline PD-1 & Promote $T$ cell anergy & Human: & Hepatocellular & [15] \\
\hline & & $\begin{array}{l}\mathrm{CD} 19+\mathrm{CD}^{\mathrm{hi}} \mathrm{CD} 24^{-/+} \\
\mathrm{CD} 27^{\mathrm{hi} /+} \mathrm{CD} 38^{\mathrm{dim}}\end{array}$ & & \\
\hline TNFa & $\uparrow \| L-10+$ Bregs, $\downarrow$ CD8 + IFNy Tcells & Mouse: & Squamous cell skin CA (mice) & [90] \\
\hline & & CD19+TNFa+ & & \\
\hline OX40L & 个Th2 skewing, $\downarrow$ CD8 + IFNy Tcells & Mouse: & Colorectal (mice) & [64] \\
\hline & & CD19+OX40L+ & & \\
\hline CD80, CD86 & $\downarrow T$ cell proliferation via interaction with & Human & Multiple tumor types & {$[30,44,69]$} \\
\hline & $\begin{array}{l}\text { CILA-4; may also } \uparrow 1 \text { cell proliferation } \\
\text { via interaction with CD28 }\end{array}$ & $\mathrm{CD} 19^{+} \mathrm{CD} 24^{\mathrm{hi}} \mathrm{CD} 38^{\mathrm{hi}}$ & & \\
\hline |L-8 & Upregulation of androgen receptor & Human: & Bladder & [22] \\
\hline & & CD19+IL-8+ & & \\
\hline FasL & Induce T cell apoptosis via binding to Fas & Human: & CLL & {$[60,61]$} \\
\hline
\end{tabular}


Table 1 Breg markers of immune suppression and tumorigenesis (Continued)

\begin{tabular}{|c|c|c|c|c|}
\hline \multirow[t]{2}{*}{ CD40L } & \multirow{2}{*}{$\begin{array}{l}\text { Interact with CD40 on malignant cells } \\
\text { to stimulate } \uparrow I L-10, \uparrow T G F \beta\end{array}$} & Human: & \multirow[t]{2}{*}{ Hepatocellular } & \multirow[t]{2}{*}{ [19] } \\
\hline & & $\mathrm{CD} 19^{+} \mathrm{CD} 24^{\mathrm{hi}} \mathrm{CD} 38^{\mathrm{hi}}$ & & \\
\hline \multirow[t]{2}{*}{ CD5 } & \multirow[t]{2}{*}{ Activation of Stat 3 via binding to IL- 6} & Human: & \multirow[t]{2}{*}{ Lung, prostate } & \multirow[t]{2}{*}{57} \\
\hline & & $\mathrm{CD}_{19} \mathrm{CD}^{+}{ }^{+} \mathrm{IL}-10+$ & & \\
\hline \multirow[t]{2}{*}{ BTK } & \multirow{2}{*}{$\begin{array}{l}\text { Repolarization of macrophages toward } \\
\text { M2-type }\end{array}$} & Mouse: & \multirow[t]{2}{*}{ Pancreatic (mice) } & \multirow[t]{2}{*}{ [82] } \\
\hline & & CD19 + BTK+ & & \\
\hline
\end{tabular}

cells in the spleen and lymph nodes compared to DMBA/ TPA-treated WT mice. Together, these results suggest that TNF $\alpha$ secretion by B cells may regulate tumor growth through production of IL- $10^{+}$Bregs, which in turn attenuate $\mathrm{CD}^{+}{ }^{+} \mathrm{IFN}-\gamma^{+} \mathrm{T}$ cell responses.

These studies suggest a unique B cell role in promoting a local inflammatory response, in turn leading to squamous carcinogenesis. Mechanisms underlying this role warrant further investigation but may involve enhanced inflammatory responses [81, 89] or local elaboration of TNF- $\alpha$ [90], both leading to enhanced myeloid cell infiltration and reduced CD8 $+\mathrm{T}$ cell infiltration. Interestingly, B cell depletion with $\alpha-C D 20$ mAb was efficacious in suppressing tumor growth as an adjunct to chemotherapy in the squamous carcinoma mouse model [80] and was efficacious as monotherapy in a mouse model of pancreatic cancer [92], however treatment with $\alpha$-CD20 mAb accelerated tumor growth in mouse breast cancer models $[64,85]$. Further investigations are warranted to determine how Breg induction may differ among tumor types and identify tumors that may be responsive to $\alpha$-CD20 mAb treatment.

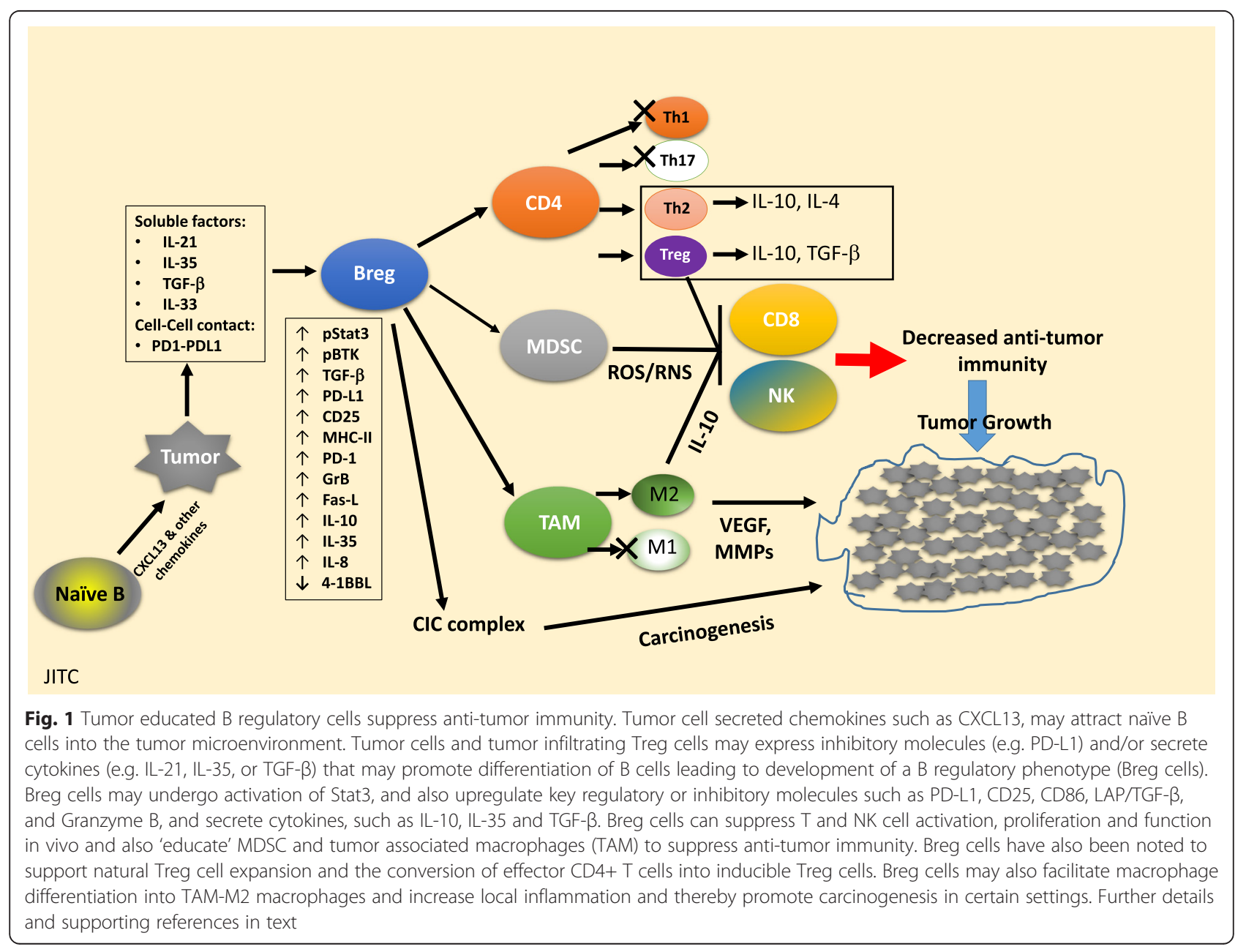


II) B cell infiltration of androgen-ablated prostate tumors in mice drives the development of castrateresistant prostate cancer

In a mouse model of prostate cancer (myc-CaP), Ammirante et al. [93] demonstrated that castration of myc-CaP tumor-bearing mice results in the accumulation of an immune infiltrate comprised of $\mathrm{B}$ and $\mathrm{T}$ lymphocytes, NK cells, and myeloid cells in dying androgen-deprived primary tumors. This process precedes the emergence of castration-resistant prostate (CR-CaP) tumors. To further explore the role of tumorinfiltrating lymphocytes (TILs) in the emergence of CR$\mathrm{CaP}$, irradiated WT mice were reconstituted with bone marrow (BM) derived from either WT or Rag1 ${ }^{-1-}$ mice and then inoculated with myc-CaP tumors, followed by castration 8 weeks later. Both groups showed identical growth of the primary tumor, however $\mathrm{CR}-\mathrm{CaP}$ tumor growth after castration was significantly delayed in mice reconstituted with $\mathrm{Rag}^{-/-} \mathrm{BM}$ compared to WT BM. More rapid emergence of CR-CaP was restored when irradiated mice were reconstituted with $\mathrm{TCR} \beta^{-1-} \mathrm{BM}$, however CR-CaP growth remained delayed when irradiated mice were reconstituted with $\mathrm{J}_{\mathrm{H}}^{-1-} \mathrm{BM}$, indicating that elimination of $\mathrm{B}$ cells rather than $\mathrm{T}$ cells was responsible for delayed growth of CR-CaP. Further mechanistic analysis revealed that secretion of lymphotoxin (LT) by infiltrating B cells stimulates LT $\beta R$ on CaP cells to induce nuclear translocation of IKK $\alpha$ and activation of STAT3, thereby driving androgen-independent tumor growth after castration. Inhibition of IKK $\alpha$, STAT3, LT $\beta R$, as well as B cell-specific LT $\beta$ ablation were each independently capable of delaying CR-CaP growth. This study invokes a completely novel mechanism by which local elaboration of a cytokine by infiltrating B cells may indirectly stimulate tumor growth. The relationship between androgen deprivation and B cell mobilization is poorly understood. Whether similar pathogenesis will be seen in human castration-resistant prostate cancer is not known.

III) B cell recruitment is regulated by HIF1 $\alpha$ stabilization and promotes tumor growth in a murine model of pancreatic ductal adenocarcinoma

Hypoxia, a central feature of the tumor microenvironment, drives the expression of hypoxia-inducible factors on tumor cells including HIF1 $\alpha$, which regulates expression of genes involved in metabolism, angiogenesis, cell survival, and inflammation [94, 95]. Lee et al. [92] showed that hypoxia-driven HIF1 $\alpha$ expression and stabilization occurred in the early growth stages of both murine Kras ${ }^{\mathrm{G} 12 \mathrm{D}}$ PDAC and human PDAC tumors, and that the deletion of pancreas-specific $\mathrm{Hif} 1 \alpha$ in mice harboring Kras ${ }^{G 12 D}$ tumors resulted in accelerated tumor growth and was associated with an influx of intrapancreatic B cells. Human PDAC tumors also showed significant intra-pancreatic B cell infiltration. B-cell depletion in $\mathrm{Kras}^{\mathrm{G} 12 \mathrm{D}} / \mathrm{HIF} 1 \alpha-\mathrm{KO}$ mice following treatment with $\alpha$ CD20 mAb significantly decreased the number of grade 3 PanIN lesions and reduced the percentage of mice with microinvasive lesions, indicating that the accelerated tumor growth in HIF1 $\alpha-\mathrm{KO}$ mice is due at least in part related to increased intrapancreatic B-cell recruitment.

Increased secretion of the B-cell chemokine CXCL13 in HIF1 $\alpha-\mathrm{KO}$ mice was believed to be responsible for the prominent influx of intrapancreatic $B$ cells, as CXCL13 levels by ELISA and immunohistochemical staining were significantly higher in $\mathrm{Kras}^{\mathrm{G} 12 \mathrm{D}} / \mathrm{HIF} 1 \alpha-\mathrm{KO}$ mice compared to Kras ${ }^{\mathrm{G} 12 \mathrm{D}}$ and WT mice. CXCL13 protein accumulation was also detected in the majority of human PDAC tumor samples.

Together, these observations indicate that hypoxia may accelerate the growth of HIF1 $\alpha$-deleted PDAC tumors in part by augmenting intrapancreatic B-cell accumulation, which appears to be driven by local expression of the $\mathrm{B}$ cell chemokine CXCL13. Therefore HIF1 $\alpha$ expression and stabilization may actually inhibit tumor B cell infiltration and thus may be a protective mechanism in response to tissue hypoxia. The effects of HIF1 $\alpha$ signaling on local $B$ cell recruitment represent a unique and unanticipated effect of hypoxia on the composition of tumor immune infiltrates and subsequent anti-tumor response.

IV) IV. B cells are actively recruited to bladder tumors and promote tumorigenesis via secretion of IL- 8

$\mathrm{Ou}$ et al. [22] demonstrated that human bladder cancer $(\mathrm{BCa})$ tissues are capable of recruiting more $\mathrm{B}$ cells than surrounding normal bladder tissues. In turn, $\mathrm{B}$ cell infiltration in BCa tissues increases BCa cell invasiveness as demonstrated in in vitro chamber invasion assays using three separate human $\mathrm{BCa}$ cell lines cocultured with $B$ cells. In addition, mice xenografted with human J82 BCa cells and co-implanted with B cells developed significantly more metastatic foci in vivo compared to mice implanted with $J 82$ cells alone.

Increased expression of androgen receptor (AR) by tumor cells was associated with increased $\mathrm{BCa}$ invasiveness. AR signaling has been implicated in bladder carcinogenesis, as androgen deprivation has been shown to inhibit tumor growth in mouse models and xenografts [96].

Further investigation revealed that B cells augment AR expression in human $\mathrm{BCa}$ tissue by secreting IL-8, a proinflammatory chemokine shown to promote bladder carcinogenesis and metastasis [97, 98]. In turn, increased AR expression leads to upregulation of the matrix metalloproteinases MMP1 and MMP13, mediators of extracellular 
collagen degradation with known roles in tumor invasion, metastasis, and BCa progression [98, 99]. Knockdown of AR expression, inhibition of MMP1 and MMP13, or the use of anti-IL-8 neutralizing antibody all reversed the ability of B cells to increase BCa cell invasion.

This study highlighted a role for local elaboration of chemokines such as IL-8 by infiltrating B cells in promoting tumor invasion. It appears that the effect of IL-8 may be to upregulate AR expression on $\mathrm{BCa}$ cells and thereby increase expression of the AR-downstream prometastatic collagenases MMP1 and MMP13. The relationship between inflammation and upregulation of AR expression is unclear. Therapeutic strategies directed against Breg secretion of IL- 8 and/or disruption of the IL-8/AR/MMP1/MMP13 pathway in BCa warrant further exploration.

\section{B regulatory cells in human solid tumor malignancies}

I) $\mathrm{CD}_{20}^{ \pm} \mathrm{B}$ cell and plasma cell infiltration of tumors have diverse effects on tumorigenesis

To date, most studies evaluating the prognostic significance of TILs have focused on T cells, while less attention has been devoted toward TIL-B cells. Using high resolution gene expression arrays, Schmidt et al. [11] showed that expression of a B cell "metagene" signature consisting of 60 genes in tumors from patients with node-negative breast cancer significantly correlated with metastasis-free survival. Tumor expression of the $\mathrm{IgG}^{+}$ plasma cell marker immunoglobulin kappa C (IGKC) provided prognostic information that was comparable with that of the B cell metagene signature in breast cancer patients. IGKC expression was also associated with better prognosis in non-small cell lung cancer (NSCLC) and colorectal adenocarcinoma (CRC) cohorts [11]. In another cohort of patients with CRC, higher density of tumor $\mathrm{CD}_{20} \mathrm{O}^{+} \mathrm{B}$ cell infiltration as measured by immunohistochemistry (IHC) correlated significantly with improved overall survival [7]. This data suggests that an immune response may actually be mediated by B cells in the aforementioned examples.

Increased tumor infiltration of $\mathrm{CD}^{2} \mathrm{O}^{+} \mathrm{B}$ cells has also been shown to portend a better prognosis among patients with epithelial ovarian cancer (EOC). Nielsen et al. [100] demonstrated that $\mathrm{CD}^{2} \mathrm{O}^{+} \mathrm{B}$ cells co-localized with $\mathrm{CD} 8+\mathrm{T}$ cells in tumor specimens from patients with high-grade serous ovarian cancer (HGSC), raising the possibility that TIL-Bs act as antigen-presenting cells to facilitate the antitumor $\mathrm{T}$ cell cytolytic response. Consistent with the hypothesis that TIL-Bs may have an antitumor effect when co-localized with $\mathrm{CD}^{+} \mathrm{T}$ cells, Kroeger et al. [10] showed that TIL-B- and T-cells colocalize and arrange in tertiary lymphoid structures
(TLS) surrounded by dense $\operatorname{IgG}^{+}$plasma cell infiltrates in HGSC tumors. CD8 ${ }^{+}$TILs conferred a better prognosis only in the presence of adjacent $C D 4^{+} \mathrm{T}$ cell TILs, $\mathrm{CD}_{20}{ }^{+} \mathrm{B}$ cell TILs, and $\mathrm{CD} 138^{+}$plasma cells. Plasma cells adjacent to TLS may confer an anti-tumor effect via antibody-related mechanisms such as complement activation or antibody-dependent cellular cytotoxicity (ADCC) [10].

In contrast to the above observations, other studies have demonstrated an increase in $\mathrm{CD}_{20}{ }^{+}$and $\mathrm{CD} 138^{+}$ cell infiltration in association with a poorer prognosis. Lundgren et al. [8] demonstrated that in patients with EOC, increased tumoral $\mathrm{CD}_{2} 0^{+}$and $\mathrm{CD} 138^{+}$expression by $\mathrm{IHC}$ was associated with advanced tumor grade, and CD138 expression correlated significantly with reduced overall and cancer-specific survival. In patients with primary operable invasive ductal breast cancer, increased CD $138^{+}$B-cell infiltration was also independently associated with poorer recurrence-free survival [23]. In patients with prostate cancer, increased tumor $\mathrm{CD}_{20}{ }^{+}$ density correlated significantly with D'Amico high-risk categorization, and was predictive of treatment failure [24]. In addition, Prueitt et al. [12] showed that immunoglobin expression by TIL-B cells was increased in active smokers with $\mathrm{PC}$, who are known to have a higher incidence of metastatic disease, compared to past or never smokers with PC.

Studies examining the prognostic significance and effects on anti-tumor immunity of tumor-infiltrating $\mathrm{CD}_{20}{ }^{+} \mathrm{B}$ cells and $\mathrm{CD} 138^{+}$plasma cells have therefore yielded conflicting results. $\mathrm{CD} 20^{+} \mathrm{B}$ cells may function to present tumor antigen to cytotoxic $\mathrm{T}$ cells or other immune effector cells, and plasma cells may secrete antibodies that aid in the immune response against tumor cells $[7,10,11,100]$. Alternatively, CD20 ${ }^{+}$and CD138 ${ }^{+}$ TIL-Bs may function to suppress $\mathrm{T}$ cell anti-tumor responses as in Bregs or promote tumor progression by nurturing an inflammatory microenvironment. Better characterization of the immunophenotype of Breg subpopulations may clarify the nature of these conflicting results.

II) Bregs are upregulated in patients with solid tumors and are associated with more aggressive disease

In contrast to the conflicting results regarding significance of general tumor infiltration with $\mathrm{CD}^{2} \mathrm{O}^{+} \mathrm{B}$ cells and $\mathrm{CD} 138^{+}$plasma cells in humans, the majority of studies examining infiltration of tumors with $B$ cells that have an established regulatory phenotype $\left(\mathrm{CD} 38^{\mathrm{hi}} \mathrm{CD} 24^{\mathrm{hi}}, \mathrm{CD} 5+\mathrm{CD} 1 \mathrm{~d}^{\mathrm{hi}}, \mathrm{CD} 24^{\mathrm{hi}} \mathrm{CD} 27^{+}, \mathrm{IL}-10^{+}\right)$ have demonstrated that Breg infiltration is associated with impaired anti-tumor immunity and more aggressive disease [13-22]. 
In patients with esophageal cancer, frequencies of peripheral blood IL- $10^{+}$Bregs were significantly greater compared with healthy controls [17]. IL- $10^{+}$Breg frequency also correlated with clinical staging and disease progression in esophageal cancer patients, as higher frequencies were seen in the peripheral blood of patients with Stage III/IV disease compared to early stage disease patients [17].

Wei et al. [16] demonstrated that in patients with ovarian cancer and ascites, CD $19^{+} \mathrm{IL}-10^{+}$Breg frequency was increased in ascitic fluid compared to peripheral blood. Furthermore, frequency of ascitic IL- $10^{+}$Bregs correlated with advanced stage and was associated with increased ascitic $\mathrm{CD} 4{ }^{+} \mathrm{FoxP}^{+}{ }^{+}$Treg frequency and decreased ascitic $\mathrm{CD} 8^{+} \mathrm{IFN}-\gamma^{+} \mathrm{T}$ cell frequency. Ex vivo, ascitic fluid $B$ cells from ovarian cancer patients suppressed IFN- $\gamma$ production by $\mathrm{CD}^{+}{ }^{+} \mathrm{T}$ cells.

Analysis of biopsy specimens from patients with tongue squamous cell carcinoma (TSCC) revealed increased frequency of $\mathrm{CD} 19^{+} \mathrm{IL}-10^{+}$Bregs in tumor tissue and metastatic lymph nodes compared to adjacent normal tissue [13]. Increased tumor $\mathrm{IL}-10^{+}$Breg frequency was also associated with increased $\mathrm{FoxP}^{+}$Treg infiltration and reduced survival.

Wang et al. [20] showed that $\mathrm{CD} 19^{+} \mathrm{CD} 24^{\mathrm{hi}} \mathrm{CD} 38^{\mathrm{hi}} \mathrm{IL}-$ $10^{+}$Bregs were more prevalent in the peripheral blood of patients with gastric cancer versus healthy controls. In gastric cancer patients, IL- $10^{+}$Bregs were more prevalent in tumor tissues versus non-tumoral tissues and peripheral blood. Ex vivo, gastric cancer Bregs suppressed IFN- $\gamma$ and TNF- $\alpha$ secretion by $\mathrm{CD}^{+}$cells and mediated conversion of $\mathrm{CD} 4^{+}$cells to $\mathrm{CD} 4^{+} \mathrm{FoxP}^{+}$Tregs via TGF- $\beta$ signaling.

In patients with $\mathrm{CRC}, \mathrm{CD} 24^{\mathrm{hi}} \mathrm{CD} 38^{\text {hi }}$ Bregs and $\mathrm{CD} 24^{\mathrm{hi}} \mathrm{CD} 27^{+}$Bregs were present in tumors and the frequency of $\mathrm{CD} 24^{\mathrm{hi}} \mathrm{CD} 38^{\mathrm{hi}}$ Bregs was significantly elevated in advanced stage tumors. Liver metastases from CRC had lower frequencies of B cells comprising the immune cell infiltrate compared to primary tumors, however the proportion of B cells with a regulatory phenotype was significantly increased in metastatic tissue, possibly indicating a shift in B cells toward a more immunosuppressive phenotype within the metastases [21].

Increased peripheral blood IL- $10^{+}$Bregs were observed in patients with NSCLC compared to healthy controls, and increased peripheral IL- $10^{+}$Bregs in NSCLC patients correlated with an increase in peripheral FoxP3 ${ }^{+}$ Tregs and MDSCs [18]. Furthermore, increased peripheral IL- $10^{+}$Breg frequency was associated with more aggressive disease progression and advanced stage. While Zhou et al. [14] also identified increased frequency of peripheral Bregs in lung cancer patients versus controls, they unexpectedly also showed decreased frequency of peripheral Tregs, but speculated that lung tissues might show increased Tregs.
In tumor specimens from patients with hepatocellular cancer (HCC), the prevalence of intrahepatic B cells at the tumor margin was associated with tumor-invasive features [19]. Peripheral blood $\mathrm{CD} 19^{+} \mathrm{CD} 24^{+} \mathrm{CD} 38^{+}$Breg frequency was significantly greater in HCC patients versus healthy controls, and circulating Breg frequency correlated with advanced staging. Higher expression levels of CD40L were observed on Bregs versus non-Bregs as well.

SCID mice injected with human MHCC-97 L HCC cells mice together with human $\mathrm{CD} 19^{+} \mathrm{CD} 24^{+} \mathrm{CD} 38^{+}$ Bregs demonstrated markedly larger tumor growth at 6 weeks and increased serum IL-10 levels compared to SCID mice injected with $\mathrm{HCC}$ cells and $\mathrm{CD} 19^{+} \mathrm{CD} 24$ ${ }^{-} \mathrm{CD} 38^{-}$non-Bregs. In in vitro co-culture studies, Bregs increased HCC cell proliferation, promoted secretion of IL- 10 and TGF- $\beta 1$ and decreased secretion of TNF- $\alpha$ compared to non-Bregs. CD40 was upregulated on HCC cells co-cultured with Bregs as well. Administration of anti-CD40L antibody blocked HCC tumor growth enhancement by Bregs in vivo, blocked enhancement of HCC cell proliferation by Bregs in vitro and decreased IL-10 and TGF- $\beta 1$ secretion while promoting an increase of TNF $\alpha$ secretion. These results suggest that an expanded $\mathrm{CD} 19^{+} \mathrm{CD} 24^{+} \mathrm{CD} 38^{+}$peripheral blood Breg population in patients with HCC may migrate to the tumor margin and mediate tumor growth via local elaboration of immunosuppressive cytokines IL-10 and TGF- $\beta$, dependent on cognate interactions between CD40L and CD40 on Bregs and HCC cells respectively. Targeting of the $\mathrm{CD} 40 \mathrm{~L} / \mathrm{CD} 40$ pathway may therefore be a possible therapeutic strategy in patients with advanced HCC.

Recently, a novel tumor-promoting PD- ${ }^{\text {high }}$ Breg subset with $\mathrm{CD} 5^{\text {high }} \mathrm{CD} 24^{-/+} \mathrm{CD} 27^{\text {high } /+} \mathrm{CD} 38^{\text {dim }}$ phenotype was identified in tumor tissues of patients with $\mathrm{HCC}$ and correlated with advanced stage and early disease progression. Investigators identified increased tumor infiltration with PD- $1^{\text {high }}$ Bregs which produced IL-10 upon interaction with PD-L1 or anti-PD1 antibody. Increased tumor infiltration with PD-1 ${ }^{\text {high }}$ IL-10-producing Bregs was associated with reduced number and dysfunction of $\mathrm{CD}^{+}$cells. These findings identify a uniquely suppressive $\mathrm{PD}-1^{+} \mathrm{B}$ cell subset in HCC pathogenesis. Therefore, PD-1 may also be viable target for the reduction of Breg activity in HCC [15].

These studies suggest that frequencies of B cells with regulatory phenotypes are increased in the peripheral blood of patients with various solid tumor types compared to age-matched controls. Also, there is evidence that B cells with regulatory phenotypes accumulate in the tumor tissues and peri-tumoral environment. It is not clear if Bregs are actively promoting tumor growth in humans or if an increase in Bregs is merely an immune response against the tumor, however aforementioned ex vivo and xenograft assays demonstrating suppressive properties of Bregs gives credence to the former hypothesis. 


\section{Conclusions}

It has become clear that in both mouse models and in humans that B cells can mediate immunosuppression through modulation of innate and/or adaptive immune responses in support of tumor growth. In several murine model systems B cells are actively recruited to tumors and directly acquire suppressive activity within the tumor bed [69]. Signaling through diverse pathways such as BTK, NF-kB and/or STAT3 has been implicated in the generation of the Breg phenotype.

A variety of cytokines secreted by Bregs have been implicated in the suppression of anti-tumor immunity including IL-10, IL-35, IL-6, and TGF- $\beta$. Additionally, Bregs may express a variety of suppressive ligands including PD-L1, PD-1, CD80, CD86, LAP-TGF- $\beta$, Fas-L, CD40L, and OX40L. Bregs may also express proteases such as Granzyme-B that directly impair T cell function [62].

Bregs may support expansion of suppressive Tregs and MDSCs, suppress stimulatory $\mathrm{Th}_{1} / \mathrm{Th}_{17}$ cells, promote skewing of T-helper cells and macrophages toward suppressive $\mathrm{Th}_{2} / \mathrm{M} 2$ types, and/or may interact directly with effector $\mathrm{CD}^{+}$and $\mathrm{CD}^{+} \mathrm{T}$ cell and/or NK cells to suppress anti-tumor immunity.

B cells may also directly promote carcinogenesis through local elaboration of inflammatory mediators such as TNF- $\alpha$ in squamous cell skin cancer [90], lymphotoxin in prostate cancer [93], and IL-8 in bladder cancer [22]. Antibody production and subsequent deposition of immune-complexes in tumor tissue is another mechanism whereby B cells may promote inflammation and neoplastic progression. B cells may also facilitate tumorigenesis through the upregulation of pro-angiogenic genes.

The list of human tumors infiltrated with B cells is rapidly expanding. $\mathrm{B}$ cell infiltration of tumors has been associated with improved prognosis or alternatively with enhanced tumor aggressiveness in different studies. Studies examining B cells with regulatory phenotypes however suggest uniformly that Breg infiltration may enhance tumor progression.

$B$ cell depletion can be accomplished using $\alpha-C D 20$ $\mathrm{mAb}$ such as rituximab and obinatuzumab, or through use of inhibitors of signal transduction such as ibrutinib.

B cell depletion strategies deployed in combination with current immune therapies requires further study. Not all forms of B cell depletion may be equally effective, as demonstrated by the failure or limited effectiveness of $\alpha$-CD20 mAb therapy in several tumor models. Further investigations are necessary to identify Bregspecific targets that may be selectively used to deplete key B cell subpopulations with regulatory function, and/ or to modulate B cell-T effector cell cross-talk through co-stimulatory ligands, cytokines, and/or chemokines to augment anti-tumor effector responses.

\section{Abbreviations}

ADCC, antibody dependent cellular cytotoxicity; $A R$, androgen receptor; B10 $B$ cells, IL-10 producing B cells; BCa, bladder cancer; BCDM, B cell deficient mice; Bregs, $B$ regulatory cells; BTK, Bruton's tyrosine kinase; CIA, collagen induced arthritis; CLL, chronic lymphocytic leukemia; CRC, colorectal adenocarcinoma; $C T L$, cytotoxic T lymphocytes; $D L B C L$, diffuse large $B$ cell lymphoma; EAE, experimental autoimmune disease; Fas-L, Fas ligand; GrB+, Granzyme-B producing Breg cells; HNSCC, head and neck squamous cell carcinoma; IBD, inflammatory bowel disease; IGKC, immunoglobulin kappa C; LLC, Lewis lung cancer; LT, lymphotoxin; MC, Myc-Cap; MDSC, myeloidderived suppressor cells; NK cells, nature killer cells; NSCLC, non-small cell lung cancer; PanIN, pancreatic intraepithelial neoplasia; PC, prostate carcinoma; PDAC, pancreatic ductal adenocarcinoma; RSV, resveratrol; SCC, squamous cell carcinoma; SLE, systemic lupus erythematosus; TAA, tumor associated antigen; TAM, tumor associated macrophages; tBregs, tumor-evoked Breg cells; TDLN, tumor draining lymph nodes; TIL, tumor infiltrating lymphocytes; TIL-B, tumor infiltrating B lymphocytes; Tregs, T regulatory cells; WT, wild type; a-CD20 mAb, anti-CD20 monoclonal antibody

\section{Acknowledgements}

Not applicable.

\section{Funding}

This project was supported by NIH program project 5P01-CA-109094-04, the Arnall Foundation and the Morgan Pressel Foundation and Women's Cancer Association.

\section{Authors' contributions}

All authors contribute to the writing, formating the data and references and final manuscript was approved by corresponding author Dr. Rosenblatt. All authors read and approved the final manuscript.

\section{Authors' information}

Not applicable.

Competing interests

The authors declare that they have no competing interests.

Consent for publication

Not applicable.

Ethics approval and consent to participate

Not applicable.

\section{Author details}

${ }^{1}$ Division of Hematology/Oncology, Department of Medicine, University of Miami Miller School of Medicine and Sylvester Comprehensive Cancer Center, 1120 NW 14th St., CRB 610, Miami, FL 33136, USA. ²Department of Medicine, University of Miami Miller School of Medicine, 1120 NW 14th St., CRB 610, Miami, FL 33136, USA. ' UM Sylvester Comprehensive Cancer Center, 1120 NW 14th St., CRB 610, Miami, FL 33136, USA.

Received: 10 June 2016 Accepted: 30 June 2016

Published online: 19 July 2016

\section{References}

1. Brodt P, Gordon J. Anti-tumor immunity in B lymphocyte-deprived mice. I. Immunity to a chemically induced tumor. J Immunol. 1978;121(1):359-62.

2. Monach PA, Schreiber H, Rowley DA. CD4+ and B lymphocytes in transplantation immunity. II. Augmented rejection of tumor allografts by mice lacking B cells. Transplantation. 1993;55(6):1356-61.

3. Qin Z et al. B cells inhibit induction of T cell-dependent tumor immunity. Nat Med. 1998:4(5):627-30.

4. Shah $\mathrm{S}$ et al. Increased rejection of primary tumors in mice lacking B cells: inhibition of anti-tumor CTL and TH1 cytokine responses by B cells. Int J Cancer. 2005;117(4):574-86.

5. Olkhanud PB et al. Tumor-evoked regulatory B cells promote breast cancer metastasis by converting resting CD4(+) T cells to T-regulatory cells. Cancer Res. 2011;71(10):3505-15. 
6. Tadmor $T$ et al. The absence of B lymphocytes reduces the number and function of T-regulatory cells and enhances the anti-tumor response in a murine tumor model. Cancer Immunol Immunother. 2011;60(5):609-19.

7. Berntsson J et al. Prognostic impact of tumour-infiltrating B cells and plasma cells in colorectal cancer. 2016. Int J Cancer.

8. Lundgren $\mathrm{S}$ et al. Prognostic impact of tumour-associated B cells and plasma cells in epithelial ovarian cancer. J Ovarian Res. 2016;9:21.

9. Milne $\mathrm{K}$ et al. Systematic analysis of immune infiltrates in high-grade serous ovarian cancer reveals CD20, FoxP3 and TIA-1 as positive prognostic factors. PLoS One. 2009;4(7):e6412.

10. Kroeger DR, Milne $\mathrm{K}$, Nelson $\mathrm{BH}$. Tumor-infiltrating plasma cells are associated with tertiary lymphoid structures, cytolytic T-cell responses, and superior prognosis in ovarian cancer. 2016. Clin Cancer Res.

11. Schmidt $M$ et al. A comprehensive analysis of human gene expression profiles identifies stromal immunoglobulin kappa C as a compatible prognostic marker in human solid tumors. Clin Cancer Res. 2012;18(9):2695-703.

12. Prueitt $R L$ et al. An immune-inflammation gene expression signature in prostate tumors of smokers. Cancer Res. 2016;76(5):1055-65.

13. Zhou X et al. CD19(+)|L-10(+) regulatory B cells affect survival of tongue squamous cell carcinoma patients and induce resting CD4(+) T cells to CD4(+)Foxp3(+) regulatory T cells. Oral Oncol. 2016;53:27-35.

14. Zhou $J$ et al. Enhanced frequency and potential mechanism of $B$ regulatory cells in patients with lung cancer. J Transl Med. 2014;12(1):304.

15. Xiao $X$ et al. PD-1High identifies a novel regulatory $B$ cell population in human hepatoma that promotes disease progression. 2016. Cancer Discov.

16. Wei $X$ et al. Regulatory $B$ cells contribute to the impaired antitumor immunity in ovarian cancer patients. Tumour Biol. 2016;37(5):6581-8.

17. Qian $L$ et al. Clinical significance of regulatory $B$ cells in the peripheral blood of patients with oesophageal cancer. Cent Eur J Immunol. 2015;40(2): 263-5.

18. Liu J et al. Aberrant frequency of IL-10-producing B cells and its association with Treg and MDSC cells in non small cell lung carcinoma patients. Hum Immunol. 2016;77(1):84-9.

19. Shao $Y$ et al. Regulatory B cells accelerate hepatocellular carcinoma progression via CD40/CD154 signaling pathway. Cancer Lett. 2014;355(2): 264-72.

20. Wang WW et al. CD19 + CD24hiCD38hiBregs involved in downregulate helper T cells and upregulate regulatory $T$ cells in gastric cancer. Oncotarget. 2015;6(32):33486-99.

21. Shimabukuro-Vornhagen A et al. Characterization of tumor-associated B-cell subsets in patients with colorectal cancer. Oncotarget. 2014;5(13):4651-64.

22. Ou Z et al. Tumor microenvironment B cells increase bladder cancer metastasis via modulation of the IL-8/androgen receptor (AR)/MMPs signals. Oncotarget. 2015;6(28):26065-78.

23. Mohammed ZM et al. The relationship between lymphocyte subsets and clinico-pathological determinants of survival in patients with primary operable invasive ductal breast cancer. Br J Cancer. 2013;109(6):1676-84.

24. Woo JR et al. Tumor infiltrating B-cells are increased in prostate cancer tissue. J Transl Med. 2014:12:30.

25. Iwata $Y$ et al. Characterization of a rare IL-10-competent B-cell subset in humans that parallels mouse regulatory B10 cells. Blood. 2011;117(2):530-41.

26. Ansell SM et al. PD-1 blockade with nivolumab in relapsed or refractory Hodgkin's lymphoma. N Engl J Med. 2015:372(4):311-9.

27. Armand $P$ et al. Disabling immune tolerance by programmed death-1 blockade with pidilizumab after autologous hematopoietic stem-cell transplantation for diffuse large B-cell lymphoma: results of an international phase II trial. J Clin Oncol. 2013;31(33):4199-206.

28. Westin JR et al. Safety and activity of PD1 blockade by pidilizumab in combination with rituximab in patients with relapsed follicular lymphoma: a single group, open-label, phase 2 trial. Lancet Oncol. 2014;15(1):69-77.

29. Qiu Z et al. Regulatory B10 cells play a protective role in severe acute pancreatitis. 2016. Inflamm Res.

30. Nova-Lamperti E et al. IL-10-produced by human transitional B-cells downregulates CD86 expression on B-cells leading to inhibition of CD4 + T-cell responses. Sci Rep. 2016;6:20044.

31. Flores-Borja F et al. CD19+CD24hiCD38hi B cells maintain regulatory T cells while limiting TH1 and TH17 differentiation. Sci Transl Med. 2013;5(173): $173 \mathrm{ra} 23$.

32. Carter NA et al. Mice lacking endogenous IL-10-producing regulatory B cells develop exacerbated disease and present with an increased frequency of Th1/ Th17 but a decrease in regulatory T cells. J Immunol. 2011;186(10):5569-79.
33. Carter NA, Rosser EC, Mauri C. Interleukin-10 produced by B cells is crucial for the suppression of Th17/Th1 responses, induction of T regulatory type 1 cells and reduction of collagen-induced arthritis. Arthritis Res Ther. 2012; 14(1):R32.

34. Mann MK et al. B cell regulation of CD4 $+\mathrm{CD} 25+\mathrm{T}$ regulatory cells and IL10 via B7 is essential for recovery from experimental autoimmune encephalomyelitis. J Immunol. 2007;178(6):3447-56.

35. Wolf SD et al. Experimental autoimmune encephalomyelitis induction in genetically B cell-deficient mice. J Exp Med. 1996;184(6):2271-8.

36. Fillatreau $S$ et al. B cells regulate autoimmunity by provision of IL-10. Nat Immunol. 2002:3(10):944-50.

37. Yanaba $K$ et al. A regulatory $B$ cell subset with a unique CD1dhiCD5+ phenotype controls T cell-dependent inflammatory responses. Immunity. 2008;28(5):639-50.

38. Mizoguchi A et al. Chronic intestinal inflammatory condition generates IL10-producing regulatory $B$ cell subset characterized by CD1d upregulation. Immunity. 2002;16(2):219-30.

39. Mauri $C$ et al. Prevention of arthritis by interleukin 10-producing B cells. J Exp Med. 2003:197(4):489-501.

40. Tao J et al. IL-10 signaling in CD4+ T cells is critical for the pathogenesis of collagen-induced arthritis. Arthritis Res Ther. 2011:13(6):R212.

41. Sattler $\mathrm{S}$ et al. IL-10-producing regulatory B cells induced by IL-33 (Breg(IL33)) effectively attenuate mucosal inflammatory responses in the gut. J Autoimmun. 2014;50:107-22

42. Rosser EC et al. Regulatory B cells are induced by gut microbiota-driven interleukin-1 beta and interleukin-6 production. Nat Med. 2014;20(11):1334-9.

43. Daien $\mathrm{Cl}$ et al. Regulatory B10 cells are decreased in patients with rheumatoid arthritis and are inversely correlated with disease activity. Arthritis Rheumatol. 2014;66(8):2037-46

44. Blair PA et al. CD19(+)CD24(hi)CD38(hi) B cells exhibit regulatory capacity in healthy individuals but are functionally impaired in systemic Lupus Erythematosus patients. Immunity. 2010;32(1):129-40.

45. Heinemann $\mathrm{K}$ et al. Decreased $\mathrm{IL}-10(+)$ regulatory $\mathrm{B}$ cells (Bregs) in lupus nephritis patients. Scand J Rheumatol. 2016:45(4):312-6.

46. Hu X et al. A lower proportion of regulatory B cells in patients with Henoch-Schoenlein Purpura Nephritis. PLoS One. 2016;11(3):e0152368.

47. Aybar LT et al. Reduced CD5(+) CD24(hi) CD38(hi) and interleukin-10(+) regulatory B cells in active anti-neutrophil cytoplasmic autoantibodyassociated vasculitis permit increased circulating autoantibodies. Clin Exp Immunol. 2015;180(2):178-88.

48. Defendenti $\mathrm{C}$ et al. B lymphocyte intestinal homing in inflammatory bowel disease. BMC Immunol. 2011;12:71.

49. Zhu HQ et al. Impaired function of CD19(+) CD24(hi) CD38(hi) regulatory B cells in patients with pemphigus. Br J Dermatol. 2015;172(1):101-10.

50. Khoder A et al. Regulatory B cells are enriched within the IgM memory and transitional subsets in healthy donors but are deficient in chronic GVHD. Blood. 2014:124(13):2034-45.

51. de Masson A et al. Deficient regulatory B cells in human chronic graftversus-host disease. Oncoimmunology. 2015;4(7):e1016707.

52. Tebbe $B$ et al. Renal transplant recipients treated with calcineurin-inhibitors lack circulating immature transitional CD19 + CD24hiCD38hi regulatory Blymphocytes. PLoS One. 2016;11(4):e0153170.

53. Salomon B, Bluestone JA. Complexities of CD28/B7: CTLA-4 costimulatory pathways in autoimmunity and transplantation. Annu Rev Immunol. 2001; 19:225-52.

54. Liu Y et al. IL-10-producing regulatory B-cells suppressed effector T-cells but enhanced regulatory T-cells in chronic HBV infection. Clin Sci (Lond). 2016; 130(11):907-19.

55. Tang Q, Bluestone JA. The Foxp3+ regulatory T cell: a jack of all trades, master of regulation. Nat Immunol. 2008;9(3):239-44.

56. Kessel A et al. Human CD19(+)CD25(high) B regulatory cells suppress proliferation of CD4(+) T cells and enhance Foxp3 and CTLA-4 expression in T-regulatory cells. Autoimmun Rev. 2012;11(9):670-7.

57. Zhang $C$ et al. CD5 binds to interleukin- 6 and induces a feed-forward loop with the transcription factor STAT3 in B cells to promote cancer. Immunity. 2016:44(4):913-23.

58. Yu H, Kortylewski M, Pardoll D. Crosstalk between cancer and immune cells: role of STAT3 in the tumour microenvironment. Nat Rev Immunol. 2007;7(1): 41-51.

59. Keir ME et al. PD-1 and its ligands in tolerance and immunity. Annu Rev Immunol. 2008;26:677-704. 
60. Lundy SK, Klinker MW, Fox DA. Killer B lymphocytes and their fas ligand positive exosomes as inducers of immune tolerance. Front Immunol. 2015;6:122.

61. Tinhofer I et al. Differential sensitivity of CD4+ and CD8+ T lymphocytes to the killing efficacy of Fas (Apo-1/CD95) ligand + tumor cells in B chronic lymphocytic leukemia. Blood. 1998;91(11):4273-81.

62. Lindner $\mathrm{S}$ et al. Interleukin 21 -induced granzyme B-expressing B cells infiltrate tumors and regulate T cells. Cancer Res. 2013;73(8):2468-79.

63. Zhang $Y$ et al. B lymphocyte inhibition of anti-tumor response depends on expansion of Treg but is independent of B-cell IL-10 secretion. Cancer Immunol Immunother. 2013;62(1):87-99.

64. Zhang $Y$ et al. B cell regulation of anti-tumor immune response. Immunol Res. 2013;57(1-3):115-24.

65. Olkhanud PB et al. Breast cancer lung metastasis requires expression of chemokine receptor CCR4 and regulatory T cells. Cancer Res. 2009;69(14): 5996-6004.

66. Wejksza K et al. Cancer-produced metabolites of 5-lipoxygenase induce tumor-evoked regulatory B cells via peroxisome proliferator-activated receptor alpha. J Immunol. 2013;190(6):2575-84.

67. Perricone MA et al. Enhanced efficacy of melanoma vaccines in the absence of B lymphocytes. J Immunother. 2004;27(4):273-81.

68. Oizumi $S$ et al. Surmounting tumor-induced immune suppression by frequent vaccination or immunization in the absence of B cells. J Immunother. 2008:31(4):394-401.

69. Zhang $Y$ et al. Mammary-tumor-educated B cells acquire LAP/TGF-beta and PD-L1 expression and suppress anti-tumor immune responses. 2016. Int Immunol.

70. Ganti SN et al. Regulatory B cells preferentially accumulate in tumordraining lymph nodes and promote tumor growth. Sci Rep. 2015;5:12255.

71. Parker KH, Beury DW, Ostrand-Rosenberg S. Myeloid-derived suppressor cells: critical cells driving immune suppression in the tumor microenvironment. Adv Cancer Res. 2015;128:95-139.

72. Bodogai $M$ et al. Immunosuppressive and prometastatic functions of myeloid-derived suppressive cells rely upon education from tumorassociated B cells. Cancer Res. 2015;75(17):3456-65.

73. Lee-Chang $C$ et al. Inhibition of breast cancer metastasis by resveratrolmediated inactivation of tumor-evoked regulatory B cells. J Immunol. 2013; 191(8):4141-51.

74. Ren $Y$ et al. JSI124 inhibits breast cancer cell growth by suppressing the function of $B$ cells via the downregulation of signal transducer and activator of transcription 3. Oncol Lett. 2014;8(2):928-32.

75. Yang $C$ et al. B cells promote tumor progression via STAT3 regulatedangiogenesis. PLoS One. 2013;8(5):e64159.

76. Pylayeva-Gupta Y et al. IL35-producing B cells promote the development of pancreatic neoplasia. Cancer Discov. 2016;6(3):247-55.

77. Wang RX et al. Interleukin-35 induces regulatory B cells that suppress autoimmune disease. Nat Med. 2014;20(6):633-41.

78. Nicholl MB et al. IL-35 promotes pancreas cancer growth through enhancement of proliferation and inhibition of apoptosis: evidence for a role as an autocrine growth factor. Cytokine. 2014;70(2):126-33.

79. Jin $\mathrm{P}$ et al. Circulating IL-35 in pancreatic ductal adenocarcinoma patients. Hum Immunol. 2014;75(1):29-33.

80. Affara $\mathrm{Nl}$ et al. B cells regulate macrophage phenotype and response to chemotherapy in squamous carcinomas. Cancer Cell. 2014:25(6):809-21.

81. Andreu $P$ et al. FcRgamma activation regulates inflammation-associated squamous carcinogenesis. Cancer Cell. 2010:17(2):121-34.

82. Gunderson AJ et al. Bruton tyrosine kinase-dependent immune cell crosstalk drives pancreas cancer. Cancer Discov. 2016;6(3):270-85.

83. Maddocks K, Jones JA. Bruton tyrosine kinase inhibition in chronic lymphocytic leukemia. Semin Oncol. 2016;43(2):251-9.

84. Tucker DL, Rule SA. Ibrutinib for mantle cell lymphoma. Future Oncol. 2016; 12(4):477-91.

85. Bodogai $M$ et al. Anti-CD20 antibody promotes cancer escape via enrichment of tumor-evoked regulatory B cells expressing low levels of CD20 and CD137L. Cancer Res. 2013;73(7):2127-38.

86. Vinay DS, Kwon BS. 4-1BB signaling beyond T cells. Cell Mol Immunol. 2011; 8(4):281-4.

87. Aklilu $\mathrm{M}$ et al. Depletion of normal B cells with rituximab as an adjunct to IL-2 therapy for renal cell carcinoma and melanoma. Ann Oncol. 2004;15(7): $1109-14$.

88. Shalapour S et al. Immunosuppressive plasma cells impede T-celldependent immunogenic chemotherapy. Nature. 2015;521(7550):94-8.
89. de Visser KE, Korets LV, Coussens LM. De novo carcinogenesis promoted by chronic inflammation is B lymphocyte dependent. Cancer Cell. 2005;7(5): 411-23.

90. Schioppa T et al. B regulatory cells and the tumor-promoting actions of TNF-alpha during squamous carcinogenesis. Proc Natl Acad Sci U S A. 2011; 108(26):10662-7.

91. Moore RJ et al. Mice deficient in tumor necrosis factor-alpha are resistant to skin carcinogenesis. Nat Med. 1999;5(7):828-31.

92. Lee KE et al. Hifla deletion reveals pro-neoplastic function of $\mathrm{B}$ cells in pancreatic neoplasia. Cancer Discov. 2016;6(3):256-69.

93. Ammirante $\mathrm{M}$ et al. B-cell-derived lymphotoxin promotes castration-resistant prostate cancer. Nature. 2010;464(7286):302-5.

94. Majmundar AJ, Wong WJ, Simon MC. Hypoxia-inducible factors and the response to hypoxic stress. Mol Cell. 2010;40(2):294-309.

95. Rankin EB, Giaccia AJ. The role of hypoxia-inducible factors in tumorigenesis. Cell Death Differ. 2008;15(4):678-85.

96. Miyamoto $\mathrm{H}$ et al. Promotion of bladder cancer development and progression by androgen receptor signals. J Natl Cancer Inst. 2007;99(7): 558-68.

97. Inoue $\mathrm{K}$ et al. Interleukin 8 expression regulates tumorigenicity and metastasis in human bladder cancer. Cancer Res. 2000;60(8):2290-9.

98. Reis ST et al. Increased expression of MMP-9 and IL-8 are correlated with poor prognosis of Bladder Cancer. BMC Urol. 2012;12:18.

99. Nabeshima K et al. Matrix metalloproteinases in tumor invasion: role for cell migration. Pathol Int. 2002;52(4):255-64.

100. Nielsen JS et al. CD20+ tumor-infiltrating lymphocytes have an atypical CD27- memory phenotype and together with CD8+ T cells promote favorable prognosis in ovarian cancer. Clin Cancer Res. 2012;18(12):3281-92.

\section{Submit your next manuscript to BioMed Central and we will help you at every step:}

- We accept pre-submission inquiries

- Our selector tool helps you to find the most relevant journal

- We provide round the clock customer support

- Convenient online submission

- Thorough peer review

- Inclusion in PubMed and all major indexing services

- Maximum visibility for your research

Submit your manuscript at www.biomedcentral.com/submit
) Biomed Central 